\title{
ENTERPRISE POTENTIAL, ENTREPRENEURIAL INTENTIONS AND ENVY
}

\author{
Terek, E., Nikolić, M., Ćoćkalo, D., Božić, S., Nastasić, A.
}

This paper presents the results of research about the impact of envy on enterprise potential and entrepreneurial intentions. The research was conducted in Serbia and the respondents were students from 5 faculties, from the first to the fifth year of study. The results were gained by statistical analysis of the gathered information (380 completed questionnaires). Descriptive, correlation and regression analysis are the methods of statistical analysis that were used. From the dimensions of enterprise potential, the highest average value has the dimension Creativity, while from the dimensions of entrepreneurial intentions, the highest average value has the dimension Subjective norm. Of all the observed dimensions, the lowest value has the Envy dimension. Between envy and dimensions of enterprise potential and dimensions of entrepreneurial intentions, there are a number of statistically significant negative correlations. This is more prevalent at the dimension of entrepreneurial intentions. Feelings of inferiority in relation to other people and the perception of having a boring or a bad life have an especially negative impact on entrepreneurial potential and intentions. Envy, which occurs due to the desire for more entertainment, travel, and due to the perception of the lack of fortune, also has a negative impact on entrepreneurial potential and intentions, but the influence is considerably weaker. There is a statistically significant predictive effect of certain items of envy on enterprise potential dimensions and entrepreneurial intentions dimensions. But this fact is not so strongly expressed. Some results suggest the possibility (however small) that envy, in some circumstances, can mildly encourage entrepreneurial intention.

Keywords: envy; enterprise potential; entrepreneurial intentions; students; Serbia JEL classification: L26, D14, I23

\section{Introduction}

There are numerous references pointing to the importance of entrepreneurship. For example, according to Mortan, Ripoll, Carvalho, \& Bernal (2014), entrepreneurship contributes to job creation, economic growth, productivity growth, competitiveness and innovation, and self-employment is an important form of professional development. Entrepreneurship is of great importance for socio-economic prosperity (Brandstätter, 2011). The reference (Gurrieri, 2013) indicates the social significance of entrepreneurship, as well as its strategic role in creating chances and new social knowledge. According to (Muzychenko (2008), in Europe, small and medium-sized enterprises, as well as entrepreneurs, have significant roles in the economy. Entrepreneurs and their innovations make a huge contribution to total national wealth (Miller, 2015). Similarly, Paul and Shrivatava (2016) indicate that entrepreneurship creates wealth and reduces unemployment.

An earlier version of this paper has been presented at the 5th International Conference Innovation Management, Entrepreneurship and Sustainability (IMES 2017) at the Faculty of Business

Administration, University of Economics, Prague. 
Entrepreneurship, therefore, contributes to self-employment and employment, reducing unemployment, increasing economic growth, productivity, competitiveness and increasing people's standards. Therefore, entrepreneurship, undoubtedly, is of great importance for every society. As carriers of these processes, entrepreneurs are needed by society and it is necessary to provide them with support and encourage people to become entrepreneurs.

However, according to Miller (2015), entrepreneurs, in addition to their positive qualities, such as energy, self-confidence, need for achievement, independence, and others, have some negative personal characteristics, which are often neglected. So entrepreneurs can sometimes manifest traits such as: aggressiveness, narcissism, ruthlessness and irresponsibility. For example, entrepreneurs usually, rightly, are associated with risk aversion. The entrepreneurs who feel anger and happiness are precisely those who are more prone to risk (Foo, 2011).

In any case, there are many different influencing factors on entrepreneurial intentions, as indicated by the reference (Geldhof et al., 2014). Due to wider national significance, it is important to examine the various impacts on the occurrence of entrepreneurial intentions and launching new business venturing. One of the negative personality traits, which may have significance on entrepreneurial intentions, is envy.

Envy is not so explored in the context of entrepreneurship. According to Mui (1995), envy can have a significant role in economic behavior. Indeed, one can raise the question of whether and how envy influenced entrepreneurial intention? On one hand, envy can inhibit entrepreneurial intentions and entrepreneurial behavior, but on the other hand, envy can also be an incentive for self-employment. The aim of this paper is to determine the direction and strength of the relationship between envy and enterprise potential, as well as the relation between envy and entrepreneurial intentions. The survey was conducted on the case of students in Serbia.

\section{Theoretical Background and Hypotheses}

\subsection{Envy}

Smith and Kim (2007) define envy as "an unpleasant, often painful emotion characterized by feelings of inferiority, hostility and resentment caused by a consciousness of a desired attribute by another person or group of persons." According to Habimana et al. (2000), envy is associated with "interpersonal conflicts, low self-esteem, depression, aggressiveness and criminal behavior such as vandalism and even murder". Similarly, Smith et al. (2007) indicate that envy is "negatively correlated with self-esteem and various measures of life satisfaction and is positively correlated with depression, neuroticism, hostility, and resentment".

According to Biniari (2012), the emergence of envy is an indication of the low level of emotional and social embeddedness. Changes and development of emotional competences, such as self-management, social awareness and relationship management have a positive impact on entrepreneurial orientation, especially on innovation and easier risk-taking (Meléndez, Fernández-Gámez, \& Gómez, 2014). This later leads to increased entrepreneurial intentions. Thus, improvement and higher levels of emotional competences have a positive impact on entrepreneurial intentions. Envy is certainly not an indication of a high level of emotional competence, so indirectly it can be concluded that the existence of envy has a negative impact on entrepreneurial intention. 
Compared to other groups, entrepreneurs, worry much less about negative facts (counterfactual thinking) and complain less about past events (Baron, 2000). At the same time, thinking about negative facts generates negative affective states (regret, resentment, envy). With these feelings, it is more difficult to enter into new ventures. Given that entrepreneurs think less about negative facts, these negative affective states are less pronounced, and therefore they easier opt for new ventures (Baron, 2000). What is of importance for this paper is that it can be concluded that entrepreneurs are less envious, compared to other people. Any envy is an indicator of negative affective states, which adversely affects entrepreneurial intentions.

Perhaps envy hampers entrepreneurship but entrepreneurship can cause envy (Choi, 1993). For example, between leadership and envy there is a correlation (Stein, 1997). Leadership is associated with attributes such as power, authority and prestige. These attributes can cause envy of colleagues and employees, as well with some friends and colleagues outside the organization where the leader works. At the same time, the leaders themselves may feel envious of their colleagues that they believe are a threat to their leadership position. No matter from which side they come, these feelings certainly have a negative effect on leadership, collaboration, and the business outcomes of an organization (Stein, 1997).

A high degree of envy among employees in organizations easily leads to interpersonal counterproductive work behavior (Cohen-Charash \& Mueller, 2007). Likewise, envy causes excessive rivalry among managers, which brings a number of negative consequences (Lehmann, 2001). Accordingly, the feelings of envy are always adversely affected by any form of business: leadership, cooperation, entrepreneurship.

\subsection{Enterprise Potential}

Enterprise potential refers to a latent tendency for a person to become an entrepreneur. That still does not mean that this person wants and has the firm intention to become an entrepreneur, but that he/she possess qualities and attitudes that are conducive to launching entrepreneurial ventures. Measuring enterprise potential is significant and a frequently researched topic in the field of entrepreneurship (Athayde, 2009). Caird (1991) developed the General Enterprise Tendency Test, which measured five entrepreneurial traits: risk talking, creativity, need for achievement, need for autonomy and internal locus of control. Here, there was a problem of staticity of personality traits, without taking into account specific situational factors (Eisen \& Fishbein, 1977; Athayde, 2009). Similarly, according to Gibb (1993), personality traits that foster entrepreneurship can be learned and developed over time, hence, they are not unchangeable. Later, there was development of a concept that included attitudes and which is considerably more dynamic than the concept that includes traits (Athayde, 2009). The concept of attitudes takes into account external factors and their changes, and not just personality traits that are assumed to be static and difficult to change.

Robinson, Stimpson, Huefner, and Hunt (1991) developed the EAO Scale (Entrepreneurial Attitude Orientation Scale) for measuring attitudes toward enterprise. This model consists of four dimensions: achievement in business, self-esteem in business, personal control of business outcomes and innovation in business. Furthermore, Peterman and Kennedy (2003) state that attitudes towards entrepreneurship are defined by three 
influential factors: perceived desirability, perceived feasibility and the propensity to act. In this paper, enterprise potential is observed and measured by a model that is based on a number of previous studies, developed by Athayde (2009). This model was originally comprised of the following five dimensions for assessing attitudes towards entrepreneurship: leadership, creativity, achievement, personal control and intuition. Later, during the formation and testing of the model, the dimension intuition was omitted.

\subsection{Entrepreneurial Intentions}

The decision to become an entrepreneur, as well as entrepreneurship, requires certain time, that is, represents a process that takes place over a specified period (Gartner, Shaver, Gatewood, \& Katz 1994). The first step of this process is the existence of entrepreneurial intention (Lee \& Wong, 2004). Similarly, Hisrich et al. (2013) believe that entrepreneurship is a complex process, consisting of several different stages, of which the formation of entrepreneurial intent is one of the most important.

According to Liñán \& Chen (2009), entrepreneurial intention has a very important role when deciding to start a business venturing, as evidenced by a significant number of scientific papers dealing with this issue. In order for a person to become an entrepreneur, he/she must first show a certain degree of entrepreneurial intent (Bird, 1988). The existence of entrepreneurial intention is a reliable predictor of entrepreneurial behavior and entrepreneurship (Koe, 2016). At the same time, the existence of a sufficient level of entrepreneurial intentions is not only an indication of future entrepreneurial behavior, but is also necessary for launching an entrepreneurial venture (Koe, 2016). On the necessity of entrepreneurial intention to achieve entrepreneurial behavior, there are many references, for example Eisen (1991), Fayolle et al. (2006) and Kolvereid (1996).

It is clear that understanding and knowledge of entrepreneurial intent is of great importance. In this way, preconditions for the development and the emergence of a larger number of entrepreneurs are created, because entrepreneurs are created and not born (Mellor et al., 2009). So, the number of entrepreneurs in different countries can be influenced by the development of entrepreneurial intentions at individuals. This will certainly have a positive impact on society. It is therefore important to study entrepreneurial intentions. In this paper, entrepreneurial intentions are measured by the entrepreneurial intention questionnaire (EIQ) (Liñán \& Chen, 2009). This questionnaire has four dimensions: personal attitude, subjective norm, perceived behavioral control and entrepreneurial intention. The first three dimensions represent motivational factors, antecedents that influence on entrepreneurial behavior (Ajzen, 1991; Liñán, 2004; Liñán \& Chen, 2009).

On the basis of previous exposure, the following hypotheses were set:

H1: There is a negative relationship between envy (items and dimension) and dimensions of enterprise potential.

H2: There is a negative relationship between envy (items and dimension) and dimensions of entrepreneurial intentions.

H3: There is a predictive effect of envy items (independent variable) on the dimensions of enterprise potential and dimensions of entrepreneurial intentions (dependent variable). 


\section{Data and Methods}

\subsection{Survey Instruments}

Envy. For the measurement of envy, the questionnaire Scale of Facebook envy was used (Tandoc, Ferrucci, \& Duffy, 2015). The questionnaire contains eight items, which constitute one dimension. Respondents classify each item ranging from 1 to 5. Items are the following: 1. I feel inferior in comparison with other people (EN1); 2. It's frustrating to watch other people always having a good time (EN2); 3. It is not fair that only some people are having fun (EN3); 4. I'd like to be able to travel as much as some of my friends do (EN4); 5. Many of my friends have a better life than me (EN5); 6. Many of my friends are happier than me (EN6); 7. My life is not as funny as the life of my friends (EN7); 8. Life is cruel and unjust (EN8).

Enterprise potential. For the measurement of enterprise potential the questionnaire that was used is the Attitude Toward Enterprise (ATE) Test (Athayde, 2009). The questionnaire has 18 items distributed in 4 dimensions. The respondents evaluated each item ranging from 1 to 7 . The dimensions are as follows: 1. Leadership (LEA); 2. Creativity (CRE); 3. Achievement (ACH); 4. Personal control (PC).

Entrepreneurial intentions. To measure entrepreneurial intentions the entrepreneurial intention questionnaire (EIQ) was used (Liñán and Chen, 2009). The questionnaire has 20 items distributed in 4 dimensions. The respondents evaluated each item ranging from 1 to 5. In this study, we used the following three aspects: 1. Subjective norm (SN); 2. Perceived behavioral control (PBC); 3. Entrepreneurial intention (EI).

\subsection{Participants and Data Collection}

The survey was conducted on a sample consisting of students of five faculties in Serbia. The biggest number of respondents were students of technical faculties and economics. In the sample, there were present about equally students from the first to the fifth year of study. The surveyed students do not have previous entrepreneurial experience. The survey was conducted during classes and questionnaires were anonymous. The survey was conducted from November 2016 till February 2017. A total of 380 valid questionnaires was collected. The age group that was interviewed ranged from 18 to 27 years. In the sample there were 237 female students and 143 male students.

\section{Results}

\subsection{Descriptive statistics}

Table 1 presents the results of descriptive statistics for the observed dimensions: Subjective norm, Perceived behavioral control, Entrepreneurial intention, Leadership, Creativity, Achievement, Personal control and Envy. In the table you can see the short name for each dimension that was used in further representation of results, number of correspondents, mean values of dimensions and standard deviation. 
Table 1 | Descriptive statistics

\begin{tabular}{|c|c|c|c|c|c|c|}
\hline & $\begin{array}{l}\text { Short } \\
\text { name }\end{array}$ & $\mathbf{N}$ & Min & Max & Mean & $\begin{array}{c}\text { Std. } \\
\text { Deviation }\end{array}$ \\
\hline Leadership & LEA & 380 & 1.00 & 7.00 & 4.250 & 1.207 \\
\hline Creativity & CRE & 380 & 2.25 & 7.00 & 5.802 & 1.038 \\
\hline Achievement & $\mathrm{ACH}$ & 380 & 1.00 & 7.00 & 4.528 & 1.172 \\
\hline Personal control & PC & 380 & 1.00 & 7.00 & 4.292 & 1.312 \\
\hline Subjective norm & SN & 380 & 1.00 & 5.00 & 3.937 & .882 \\
\hline $\begin{array}{l}\text { Perceived } \\
\text { behavioral control }\end{array}$ & PBC & 380 & 1.00 & 5.00 & 3.502 & .701 \\
\hline $\begin{array}{l}\text { Entrepreneurial } \\
\text { intention }\end{array}$ & $\mathrm{El}$ & 380 & 1.00 & 5.00 & 3.522 & .839 \\
\hline Envy & EN & 380 & 1.00 & 4.75 & 2.265 & .736 \\
\hline Valid N (list wise) & & 380 & & & & \\
\hline
\end{tabular}

\subsection{Correlation Analysis}

Correlation analysis was performed between envy items (respectively) and envy dimensions on the one hand, and enterprise potential dimensions and entrepreneurial intentions dimension on the other hand. Pearson Correlation was used. The results of the correlation analysis are given in Table 2.

Table 2 | Pearson coefficients of correlation between envy (items and dimension) and dimensions of enterprise potential and dimensions of entrepreneurial intentions

\begin{tabular}{|l|c|c|c|c|c|c|c|}
\hline & LEI & CRE & ACH & PC & SN & PBC & EI \\
\hline EN1 & $-.215^{* *}$ & -.038 & $-.271^{* *}$ & $-.103^{*}$ & -.091 & $-.191^{* *}$ & $-.124^{*}$ \\
\hline EN2 & -.096 & .018 & $-.147^{* *}$ & -.034 & $-.178^{* *}$ & $-.120^{*}$ & $-.103^{*}$ \\
\hline EN3 & -.011 & .053 & -.019 & -.036 & .043 & .009 & .048 \\
\hline EN4 & -.042 & $.181^{* *}$ & -.035 & -.005 & $-.125^{*}$ & -.074 & -.065 \\
\hline EN5 & -.024 & .055 & -.063 & -.059 & $-.253^{* *}$ & $-.181^{* *}$ & $-.199^{* *}$ \\
\hline EN6 & -.033 & .032 & -.089 & -.001 & $-.199^{* *}$ & $-.130^{*}$ & $-.114^{*}$ \\
\hline EN7 & $-.140^{* *}$ & -.013 & $-.156^{* *}$ & -.048 & $-.146^{* *}$ & $-.173^{* *}$ & $-.179^{* *}$ \\
\hline EN8 & -.093 & .003 & -.085 & -.042 & -.086 & $-.130^{*}$ & -.051 \\
\hline EN & $-.114^{*}$ & .060 & $-.148^{* *}$ & -.058 & $-.184^{* *}$ & $-.175^{* *}$ & $-.136^{* *}$ \\
\hline
\end{tabular}

Note: * correlations significant at the level $0.01,{ }^{* *}$ - correlation significant at the level 0.05 . 


\subsection{Regression analysis}

Predictive effect of envy on the dimensions of enterprise potential and dimension of entrepreneurial intentions is determined via Multiple Regression Analysis. Whereas the envy (items and dimension) are independent variables, while dimensions of enterprise potential and dimensions of entrepreneurial intentions are dependent variables. Table 3 shows the results of the regression analysis.

Table 3 | Regression analysis (Independent Variable: envy - items and dimension, Dependent Variable: dimensions of enterprise potential and dimensions of entrepreneurial intentions)

\begin{tabular}{|c|c|c|c|c|c|c|c|c|c|c|c|}
\hline \multirow{3}{*}{$\begin{array}{l}\text { Dep. } \\
\text { Var. }\end{array}$} & \multicolumn{8}{|c|}{ Independent Variable } & \multirow{3}{*}{$\mathbf{R}^{2}$} & \multirow{3}{*}{$\mathbf{F}$} & \multirow{3}{*}{ Sig. } \\
\hline & EN1 & EN2 & EN3 & EN4 & EN5 & EN6 & EN7 & EN8 & & & \\
\hline & \multicolumn{8}{|c|}{$\beta$} & & & \\
\hline LEA & $-.220^{* *}$ & -.029 & .097 & -.031 & .085 & .158 & $-.185^{*}$ & -.103 & .079 & 3.962 & .000 \\
\hline CRE & -.059 & -.010 & .030 & $.206^{* *}$ & .002 & .056 & -.083 & -.051 & .044 & 2.126 & .003 \\
\hline $\mathrm{ACH}$ & $-.256^{*}$ & -.070 & .106 & -.002 & .073 & 0.81 & -.130 & -.072 & .092 & 4.722 & .000 \\
\hline PC & -.114 & .026 & -.023 & .042 & -.123 & .166 & -.051 & -.036 & .022 & 1.061 & 0.390 \\
\hline SN & .043 & $-.198^{* *}$ & $.213^{*}$ & -.037 & -.212 & -.012 & -.011 & .001 & .103 & 5.308 & .000 \\
\hline PBC & $-.138^{* *}$ & -.050 & $.139^{*}$ & .008 & -.148 & .142 & -.129 & -.091 & .076 & 3.794 & .000 \\
\hline EI & -.047 & -.076 & .169 & .014 & $-.242^{* *}$ & $.193^{* *}$ & $-.189^{* *}$ & .007 & .080 & 4.059 & .000 \\
\hline
\end{tabular}

Note: ${ }^{*}-\beta$ coefficients significant at the level $0.01,{ }^{* *}-\beta$ coefficients significant at the level 0.05 .

\section{Discussion}

The results of the descriptive statistics (Table 1) show that, with the dimensions of enterprise potential, the highest average value has the Creativity dimension. It is obvious that students highly value creativity and consider themselves as creative. It is possible that in this dimension there is a certain degree of subjectivity, since most students consider themselves to be creative. The other three dimensions of enterprise potential have mean values slightly above average, so it can be concluded that there is a balance between the distributions of these features in students. When it comes to the dimensions of entrepreneurial intentions, the highest average value has the dimension of the Subjective norm. This can be considered expected because students believe that an entrepreneur's job brings numerous benefits. However, it is easier to want to become an entrepreneur than really have a strong desire to achieve it. That is why the other two dimensions have lower average values, but they are above average, and this is what gives some optimism.

The Envy dimension has a low average value and, in general, can be considered as a good result. This value is lower than that obtained in some other studies (Tandoc et al., 2015; Wohn et al., 2014). The explanation for this situation should be sought in the fact that young people are healthy, ambitious, smart and positive. In addition, this result is very likely contributed to by the collectivist national culture in Serbia (Vukonjanski, 
Nikolić, Hadžić, Terek, \& Nedeljković, 2012), which encourages communion and solidarity, which again reduce envy.

Table 2 shows the results of the correlation analysis. It can be seen that dominant are the negative correlations, and there is a bigger number of statistically significant negative correlations. This is especially true for the dimension of entrepreneurial intentions. Based on these results, we can say that hypotheses $\mathrm{H} 1$ and $\mathrm{H} 2$ are verified, especially hypothesis $\mathrm{H} 2$.

From the envy items, the strongest negative correlation has the item EN1 - I feel inferior in relation to other people, then items EN7 - My life is not as fun as the lives of my friends and EN5 - Many of my friends have a better life than me. Indeed, it is difficult to imagine in the role of entrepreneur, especially a successful entrepreneur, people who have a sense of inferiority in relation to other people. This feeling is definitely not conducive to entrepreneurship. The situation is similar with people who see their lives as boring and as worse than some other people have. It may be expected that the perception of a bad life may seem motivating, but this does not happen. It should be noted that the dimension envy has fairly high negative correlations that are in accordance with the results of envy items. From envy items at least negative correlations have the item EN3 It's not fair that only some people are having fun (This item has actually positive, but not statistically significant correlations), then items EN4 - I'd love to travel as much as some of my friends and EN8 - Life is harsh and unfair. These three items can describe people who are less fortunate, do not have rich parents, need to work harder and similar things. These people still should not be dismissed as future entrepreneurs, in fact, they should be encouraged and given a chance to start their own business.

From enterprise potential dimensions and entrepreneurial intentions dimensions, the strongest negative correlations occur at dimensions SN - Subjective norm and at dimensions PBC - Perceived behavioral control and ACH - Achievement. Apparently the lack of support from family, friends and colleagues leads to increased envy. It is possible that increased envy causes little support by the environment. Also, the lack of confidence in their own abilities and energy to achieve goals foster envy. It is interesting to note thet in Table 2 there is a statistically significant but positive correlation. This occurs between the item EN4 - I'd love to be able to travel as much as some of my friends and dimension CRE - Creativity. The desire to travel does not have to be necessarily viewed as an indicator of envy, but as a positive tendency to learn about different countries, cultures, people, traditions, food, to experience different adventures. Therefore, it is logical that these desires are associated with creativity.

The results of regression analysis (Table 3 ) show that there is a statistically significant predictive effect of certain items of envy on the enterprise potential dimensions and entrepreneurial intentions dimensions. However, this fact is not so strongly expressed. Accordingly, the value of the corrected index determination $\mathrm{R}^{2}$ is quite low and ranges between 0.022 and 0.103 . It can be concluded that hypothesis H3 is partially confirmed.

The results of regression analysis are generally consistent with the results of correlation analysis. However, there is one interesting exception: a statistically significant positive predictive effect of item EN6 - Many of my friends are happier than me to the dimension of EI - Entrepreneurial intention. Here we can see a slight hint that envy in some complex relationships and in a broader context can contribute to the development of entrepreneurial intentions. Thus, it should be borne in mind that envy, in some situations and circumstances, can mildly encourage entrepreneurial intention. 


\section{Conclusion}

From the dimensions of enterprise potential, the highest average value has the dimension of Creativity, while from the dimensions of entrepreneurial intentions, the highest average value has the dimension of the Subjective norm. Of all the dimensions observed, the lowest value has the dimension Envy.

Between envy (items and dimension) and dimensions of enterprise potential and dimensions of entrepreneurial intentions, there is a bigger number of statistically significant negative correlation. This is more prevalent at the dimension of entrepreneurial intentions. Feelings of inferiority in relation to other people as well as the perception of boring and bad of life have an especially negative impact on entrepreneurial potential and intentions. From the standpoint of entrepreneurial potential and intentions, envy is aggravated due to poor support from family, friends and colleagues, as well as a lack of confidence and vigor.

On the other hand, envy, which occurs due to the desire for more entertainment, travel, and due to the perception of the lack of fortune, also has a negative impact on the entrepreneurial potential and intentions, but this influence is much weaker. At the same time, the results of the regression analysis indicate a low possibility that envy, in some circumstances, can slightly encourage people towards entrepreneurial intention. Based on these results, it is recommended that people should not, from the very beginning, write off all the envious people as not suitable for entrepreneurship. There should be identified those in whom envy is not strong and where there is a possibility that such envy could be turned into motivation. With adequate support and understanding, these people may be a potential future entrepreneurs.

\section{References}

Ajzen, I., \& Fishbein, M. (1977). Attitude-behavior relations: A theoretical analysis and review of empirical research, Psychological Bulletin, 84, 888-918.

Ajzen, I. (1991). The theory of planned behavior. Organizational Behavior and Human Decision Processes, 50(2), 179-211.

Athayde, R. (2009). Measuring Enterprise Potential in Young People. Entrepreneurship Theory and Practice, 33(2), 481-500.

Baron, R. A. (2000). Counterfactual thinking and venture formation: The potential effects of thinking about "what might have been". Journal of Business Venturing, 15(1), 79-91.

Biniari, M. G. (2012). The emotional embeddedness of corporate entrepreneurship: the case of envy. Entrepreneurship Theory and Practice, 36(1), 141-170.

Bird, B. (1988). Implementing entrepreneurial ideas: The case for intentions. Academy of Management Review, 13, 442-453.

Brandstätter, H. (2011). Personality aspects of entrepreneurship: A look at five meta-analyses. Personality and Individual Differences, 51(3), 222-230.

Caird, S. (1991). Testing enterprise tendency in occupational groups. British Journal of Management, 12, 177-186.

Choi, Y. B. (1993). Entrepreneurship and envy. Constitutional Political Economy, 4(3), 331-347.

Cohen-Charash, Y., \& Mueller, J. (2007). Does Perceived Unfairness Exacerbate or Mitigate Interpersonal Counterproductive Work Behaviors Related to Envy? Journal of Applied Psychology, 92(3), 666-680. 
Fayolle, A., Gailly, B., \& Lassas-Clerc, N. (2006). Assessing the impact of entrepreneurship education programmes: A new methodology. Journal of European Industrial Training, 30(9), 701-720.

Foo, M. D. (2011). Emotions and entrepreneurial opportunity evaluation. Entrepreneurship Theory and Practice, 35(2), 375-393.

Gartner, W. B., Shaver, K. G., Gatewood, E. J., \& Katz, J. (1994). Finding the entrepreneur in entrepreneurship. Entrepreneurship Theory and Practice, 18(3), 5-10.

Geldhof, G. J., Malin, H., Johnson, S. K., Porter, T., Bronk, K. C., Weiner, M. B., Agans, J. P., Mueller, M. K., Hunt, D., Colby, A., Lerner, R. M., \& Damon, W. (2014). Entrepreneurship in young adults: Initial findings from the young entrepreneurs study. Journal of Applied Developmental Psychology, 35(5), 410-421.

Gibb, A. (1993). The enterprise culture and education. International Small Business Journal, 11(3), 11-34.

Gurrieri, A. R. (2013). Networking entrepreneurs. The Journal of Socio-Economics, 47, 193-204.

Habimana, E., \& Masse, L. (2000). Envy manifestations and personality disorders. European Psychiatry, 15, 15-21.

Hisrich, R. D., Peters, M. P., \& Shepherd, D. A. (2013). Entrepreneurship (9th ed.). New York: McGraw Hill.

Koe, W. L. (2016). The relationship between Individual Entrepreneurial Orientation (IEO) and entrepreneurial intention. Journal of Global Entrepreneurship Research, 6(1), 13.

Kolvereid, L. (1996). Prediction of employment status choice intentions. Entrepreneurship Theory and Practice, 21(1), 47-57.

Lee, S. H., \& Wong, P. K. (2004). An exploratory study of technopreneurial intentions: A career anchor perspective. Journal of Business Venturing, 19(1), 7-28.

Lehmann, D. R. (2001). The impact of altruism and envy on competitive behavior and satisfaction. International Journal of Research in Marketing, 18, 5-17.

Liñán, F. (2004). Intention-based models of entrepreneurship education. Piccola Impresa/Small Business, 2004(3), 11-35.

Liñán, F., \& Chen, Y. W. (2009). Development and Cross-Cultural Application of a Specific Instrument to Measure Entrepreneurial Intention. Entrepreneurship Theory and Practice, 33(3), 593-617.

Meléndez, A. P., Fernández-Gámez, M. A., \& Gómez, J. M. (2014). Feeling the risk: effects of the development of emotional competences with outdoor training on the entrepreneurial intent of university students. International Entrepreneurship and Management Journal, 10(4), 861-884.

Miller, D. (2015). A downside to the entrepreneurial personality. Entrepreneurship Theory and Practice, 39(1), 1-8.

Mellor, R., Coulton, G., Chick, A., Bifulco, A., Mellor, N., \& Fisher, A. (2009). Entrepreneurship for Everyone. London: SAGE Publications.

Mortan, R. A., Ripoll, P., Carvalho, C., \& Bernal, M. C. (2014). Effects of emotional intelligence on entrepreneurial intention and self-efficacy. Journal of Work and Organizational Psychology, 30, 97-104.

Mui, V. L. (1995). The economics of envy. Journal of Economic Behavior and Organization, 26, 311-336.

Muzychenko, O. (2008). Cross-cultural entrepreneurial competence in identifying international business opportunities. European Management Journal, 26(6), 366-377. 
Paul, J., \& Shrivatava, A. (2016). Do young managers in a developing country have stronger entrepreneurial intentions? Theory and debate. International Business Review, 25(6), 1197-1210.

Peterman, N. E., \& Kennedy, J. (2003). Enterprise education: Influencing students' perceptions of entrepreneurship. Entrepreneurship Theory and Practice, 28(2), 129-144.

Robinson, P. B., Stimpson, D. V., Huefner, J. C., \& Hunt, H. K. (1991). An attitude approach to the prediction of entrepreneurship. Entrepreneurship Theory and Practice, 15(4), 13-31.

Smith, R. H., \& Kim, S. H. (2007). Comprehending Envy. Psychological Bulletin, 133(1), 46-64.

Stein, M. (1997). Envy and Leadership. European Journal of Work and Organizational Psychology, 6(4), 453-465.

Tandoc, E. C. Jr., Ferrucci, P., \& Duffy, M. (2015). Facebook use, envy, and depression among college students: Is Facebooking depressing? Computer in Human Behavior, 43, 139-146.

Vukonjanski, J., Nikolić, M., Hadžić, O., Terek, E., \& Nedeljković, M. (2012). Relationship between GLOBE organizational culture dimensions, job satisfaction and leader-member exchange in Serbian organizations. Journal for East European Management Studies. 17(3), 333-368.

Wohn, D. Y., \& LaRose, R. (2014). Effects of loneliness and differential usage of Facebook on college adjustment of first-year students. Computers and Education, 76(2014) 158-167.

\section{Authors}

\section{Edit Terek}

University of Novi Sad

Technical Faculty "Mihajlo Pupin"

Djure Djakovića bb, 23000

Zrenjanin, Serbia

edit@tfzr.uns.ac.rs; terekedita@gmail.com

\section{Milan Nikolić}

University of Novi Sad

Technical Faculty "Mihajlo Pupin"

Djure Djakovića bb, 23000

Zrenjanin, Serbia

milan.nikolic@tfzr.uns.ac.rs; mikaczr@sbb.rs

\section{Dragan Ćoćkalo}

University of Novi Sad

Technical Faculty "Mihajlo Pupin”

Djure Djakovića bb, 23000

Zrenjanin, Serbia

cole@tfzr.uns.ac.rs

\section{Sanja Božić}

University of Novi Sad

Faculty of Science

Trg Dositeja Obradovića 6, 21000

Novi Sad, Serbia

sanja.bozic@dgt.uns.ac.rs 


\section{Aleksandra Nastasić}

Belgrade Polytechnic

Brankova 17, 11000

Belgrade, Serbia

anastasic@politehnika.edu.rs

This paper is a result of the research activities conducted under the project "Improving the entrepreneurial climate, analysis of aspects and possible plans of action at young people in the region of Central Banat", which is financed by the Provincial secretariat for higher education and scientific research of Autonomous Province of Vojvodina, Republic of Serbia. 